\title{
HIV enteropathy: comparative morphometry of the jejunal mucosa of HIV infected patients resident in the United Kingdom and Uganda
}

P A Batman, M S Kapembwa, A R O Miller, P M Sedgwick, S Lucas, N K Sewankambo, D Serwadda, J Pudney, A Moody, J R W Harris, G E Griffin

Bradford Royal Infirmary, Bradford P A Batman

Northwick Park Hospital, Harrow M S Kapembwa

Kidderminster General Hospital A R O Miller

St George's Hospital Medical School, London

P M Sedgwick

G E Griffin

St Thomas's Hospital, London

S Lucas

Department of Clinical Parasitology, Hospital for Tropical Diseases, London

A Moody

St Mary's Hospital Medical School, London, UK J R W Harris

Makerere University Faculty of Medicine, Kampala, Uganda N K Sewankambo D Serwadda

Harvard Medical School, Boston, USA J Pudney

Correspondence to: Dr P A Batman, Consultant Histopathologist, Bradford Royal Infirmary, Bradford, UK.

Accepted for publication 23 March 1998

\begin{abstract}
Aims-To compare jejunal mucosal morphometry in HIV infected patients resident in London and Uganda.

Patients-Twenty HIV positive patients from London and 16 from Uganda were studied, and compared with HIV negative control subjects from both sites.

Methods-Stools and biopsy specimens were examined for enteropathogens. Surface area to volume $(\mathrm{S}: \mathrm{V})$ ratio was estimated morphometrically, mean crypt length of jejunal biopsy specimens was measured, and HIV infected cells detected immunohistochemically were quantified. Results-Enteric pathogens were detected in none of the London patients, and in three Ugandan patients. $S: V$ ratio was lower, and mean crypt length higher, in the specimens of London patients than in normal subjects, but there was no difference in $S: V$ ratio or mean crypt length between Ugandan patients and controls. A negative correlation was present between $S: V$ ratio and mean crypt length in all biopsy specimens analysed. HIV infected cells were detected only in lamina propria. Conclusion-Infection of cells in the lamina propria of the jejunum with HIV stimulates crypt cell proliferation, and a fall in villous surface area. The mucosal response to HIV is masked by other pathogens in the African environment.

(Gut 1998;43:350-355)
\end{abstract}

Keywords: HIV; jejunum; AIDS; enteropathy

The majority of patients with AIDS suffer from gastrointestinal disease. Common clinical features are diarrhoea, malabsorption, and weight loss. ${ }^{1}$ The mechanisms involved in gastrointestinal disease in these patients are undoubtedly multifactorial, involving the interplay of opportunistic infection, malabsorption of nutrients, reduced food intake, metabolic alterations, and possibly tissue damage inflicted by HIV itself. ${ }^{2}{ }^{3}$ Over a decade since it was postulated that HIV might damage small intestinal structure and function, ${ }^{45}$ the concept of HIV enteropathy remains controversial. Some authors maintain that significant small intestinal disease in patients infected with HIV is caused solely by opportunistic infection ${ }^{6}$; other work provides evidence that HIV is an enteric pathogen in its own right..$^{8-14}$ Similarly, there is a consensus view that the small intestine of patients infected with
HIV may show villous atrophy, ${ }^{6-11}{ }^{14}$ but there is no such agreement on the effect of HIV on small intestinal crypt length ${ }^{8-11}{ }^{14}$; consequently there are several divergent views about the aetiology and pathogenesis of jejunal villous atrophy in patients with HIV disease. This study aims to measure and compare these two parameters of mucosal structure, villous surface area and crypt length, in HIV infected patients resident in a temperate and in a tropical climate. Comparison of these two groups of patients sheds light on the biology of the small intestine in different environments and its response to pathogens, including HIV.

\section{Materials and methods}

SUBJECTS

Table 1 summarises clinical data for the London and African patients. All patients gave informed written consent to participation in the study. The study protocol was approved by independent ethics committees at St George's and St Mary's Hospitals, London, and Mulago Teaching Hospital.

\section{London patients}

Twenty consecutive HIV positive homosexual male Caucasian patients (mean age 37 years, range 20-56) residing in London and attending St George's and St Mary's Hospitals, London, were investigated. All subjects were HIV antibody positive (Wellcome Diagnostics). Patients were classed as asymptomatic (constitutionally well) or suffering from HIV related illness according to the Centers for Disease Control criteria. ${ }^{15}$ Each subject provided a stool specimen on the study day. Subjects were specifically asked whether they had normal formed stool with unchanged bowel habit, or mild, moderate, or severe diarrhoea based on stool frequency (mild $<3$ stools/day, moderate 4-6 stools/day, and severe $>6$ stools/day for a period in excess of four weeks).

Stool examination-Stools collected shortly before jejunal biopsy were cultured and examined microscopically for enteropathogens. Stool specimens were cultured for Salmonellae, Shigellae, Campylobacter sp, Aeromonas sp, Plesiomonas sp, and Clostridium difficile, and a special culture on Lowenstein-Jensen medium was carried out. Stool samples were examined microscopically for neutrophils, ova, and parasites. Ziehl-Neelsen and modified ZiehlNeelsen stains were used to identify Mycobacteria, Cryptosporidia, and Isospora.

Control subjects-Jejunal biopsy specimens were obtained by Crosby capsule from seven 
age and sex matched London control subjects. These specimens were taken from subjects who were subsequently diagnosed as suffering from irritable bowel syndrome, and were judged to be normal at light microscopic examination by two experienced histopathologists. HIV antibody testing was not carried out on control subjects for ethical reasons but no control subject was considered to belong to any high risk group and none had any clinical stigmata of HIV infection.

African subjects

A group of 16 consecutive HIV antibody positive heterosexual Ugandan males (mean age 29 years, range 20-52) at Mulago Hospital, a teaching hospital for Makerere Medical School, were also studied. Centres for Disease Control criteria for definition of AIDS could not be applied due to the limited diagnostic resources available, and so the World Health Organisation (WHO) clinical case definition was used. $^{16}$ Each subject provided a stool specimen on the study day and a history including gastrointestinal symptoms was taken.

Stool examination-Three air dried smears from the faecal specimen from each HIV antibody positive subject were examined microscopically for ova, cysts, and parasites. ZiehlNeelsen and modified Ziehl-Neelsen stains were used to identify Mycobacteria, Cryptosporidia, and Isospora.

Control subjects-Seven male HIV antibody negative heterosexual Ugandan Africans (mean age 25 years, range 21-30) living in Kampala and forming a seroepidemiological study were used as control subjects. The HIV antibody status of subjects was determined by the enzyme linked immunosorbent assay (ELISA) method (Wellcome) and confirmed by western blotting.

JEJUNAL BIOPSY

Jejunal biopsy specimens obtained by Crosby capsule from all test and control subjects were processed routinely to paraffin wax, and sections $3 \mu \mathrm{m}$ thick were cut from the blocks. Ten sections taken at regular intervals through the block were stained with haematoxylin and eosin for subjective light microscopic examination and for quantitation of mucosal surface area to volume ratio.

One section from each biopsy specimen was stained with periodic acid Schiff (PAS), Giemsa, modified Ziehl-Neelsen, and BrownBrenn stain for detection of mucosal enteropathogens.

A separate portion of the jejunal biopsy specimen from each London patient was fixed in $2.5 \%$ glutaraldehyde cacodylate buffer $(\mathrm{pH}$ 7.4) and processed for transmission electron microscopy. Ultrathin sections were examined for the presence of Microsporidia and ultrastructural abnormalities in epithelial cells.

MUCOSAL QUANTITATION

Mucosal architecture index

Observations were carried out while unaware of the clinical HIV status of subjects. The ratio of surface area of villi to volume of lamina pro- pria in the jejunal biopsy specimens from London and African patients and control subjects was estimated by a Weibel eyepiece graticule. ${ }^{17}$ The graticule was viewed superimposed on the jejunal mucosa at a constant magnification $(\times 100)$ at several fields along the length of the biopsy specimen and at 10 levels through the block. The surface area to volume ratio $(\mathrm{S}: \mathrm{V}$ ratio) was calculated for each biopsy specimen and expressed as the mucosal architecture index.

\section{Crypt length}

Observations were carried out while unaware of the clinical HIV status of patients or the $\mathrm{S}: \mathrm{V}$ ratio of the mucosa. Crypt length (crypt column) was assessed by counting the number of enterocytes along one side of the crypt from its base to its junction with a villus. ${ }^{18-20}$ This count was repeated in an average of 38 crypts (range 13-50) from the biopsy specimens from London and African patients and control subjects and a mean crypt length (CL) calculated.

\section{HIV infected cells}

Jejunal mucosal biopsy specimens were examined from $10 \mathrm{HIV}$ positive London and African patients and from three control subjects from each group.

Sections were incubated with a cocktail of primary monoclonal antibodies (p24 and p55), and antibodies were visualised using an alkaline phosphatase/antialkaline phosphatase (AP/ AAP) system. ${ }^{21}$ To visualise the antibodies, the sections were then incubated in the substrate Fast Red, staining positive cells red. Positive control specimens consisted of HIV infected Jurkat cells; negative control specimens comprised jejunal biopsy specimens and HIV infected Jurkat cells processed in the absence of the primary monoclonal antibody, which was replaced with either the antibody diluent or an irrelevant IgG.

Several (5-25) sections, $3 \mu \mathrm{m}$ in thickness, from each mucosal biopsy specimen were stained and the total number of HIV infected cells in each biopsy specimen was counted. The total length of the muscularis mucosae in each biopsy specimen was measured using a Seescan image analyser (Seescan RLC, Cambridge, UK), and the total area of muscularis mucosae (length $\times$ thickness $(3 \mu \mathrm{m})$ ) was calculated. The approximate area of muscularis mucosae supporting each HIV infected cell was estimated for each biopsy specimen. The mucosal density of HIV infected cells (cells per unit area of muscularis mucosae) was then taken as the reciprocal of this value.

\section{STATISTICS}

The Wilcoxon rank sum test with an approximation to the normal distribution was used to test whether two independent groups were drawn from the same population, with the test statistic denoted by s. Spearman's rank order correlation coefficient $(r)$ was used to test for association between two variables. The mean (2SD) is used to illustrate the main expanse of a sample. Statistical significance was set at the $5 \%$ level. Results are stated as mean (SD). 
Table 1 Clinical data and mucosal density of HIV infected cells

\begin{tabular}{|c|c|c|c|c|c|}
\hline HIV stage & Clinical features & $\begin{array}{l}\text { Stool } \\
\text { microbiology }\end{array}$ & $\begin{array}{l}\text { Biopsy } \\
\text { microbiology }\end{array}$ & $\begin{array}{l}\text { No of } \\
\text { positive } \\
\text { cells }\end{array}$ & $\begin{array}{l}\text { Density of } \\
\text { positive } \\
\text { cells }\end{array}$ \\
\hline \multicolumn{6}{|l|}{ London patients } \\
\hline Asymptomatic & Mild diarrhoea & Nil & Nil & - & - \\
\hline Asymptomatic & Moderate diarrhoea & Nil & Nil & - & - \\
\hline Asymptomatic & Mild diarrhoea & Nil & Nil & - & - \\
\hline Asymptomatic & Mild diarrhoea & Nil & Nil & - & - \\
\hline Asymptomatic & Moderate diarrhoea & Nil & Nil & - & - \\
\hline PGL & Moderate diarrhoea & Nil & Nil & - & - \\
\hline PGL & No diarrhoea & Nil & Nil & - & - \\
\hline PGL & Mild diarrhoea & Nil & Nil & - & - \\
\hline ARC & Severe diarrhoea & Nil & Nil & - & - \\
\hline ARC & Moderate diarrhoea & Nil & Nil & - & - \\
\hline ARC & Severe diarrhoea & Nil & Nil & - & - \\
\hline ARC & Moderate diarrhoea & Nil & Nil & - & - \\
\hline ARC & No diarrhoea & Nil & Nil & - & _- \\
\hline $\mathrm{ARC}$ & Moderate diarrhoea & Nil & Nil & - & - \\
\hline AIDS & Severe diarrhoea & Nil & Nil & - & - \\
\hline AIDS & No diarrhoea & Nil & Nil & 1 & 2 \\
\hline AIDS & Mild diarrhoea & Nil & Nil & 5 & 25 \\
\hline AIDS & Severe diarrhoea & Nil & Nil & 0 & $<5$ \\
\hline AIDS & Mild diarrhoea & Nil & Nil & - & - \\
\hline AIDS & No diarrhoea & Nil & Nil & - & - \\
\hline \multicolumn{6}{|l|}{ African patients } \\
\hline ARC & Diarrhoea, weight loss & Nil & Nil & 40 & 143 \\
\hline ARC & Diarrhoea, weight loss & Nil & Nil & - & - \\
\hline ARC & Diarrhoea, weight loss & Nil & Nil & 23 & 143 \\
\hline ARC & Diarrhoea & Nil & Nil & - & - \\
\hline ARC & Abdominal pain & Nil & Nil & - & - \\
\hline ARC & Diarrhoea, weight loss & Nil & Nil & - & - \\
\hline AIDS & Diarrhoea, weight loss & Nil & Nil & 24 & 62 \\
\hline AIDS & Herpes zoster & Nil & Nil & 12 & 50 \\
\hline AIDS & Hemiparesis & Nil & Nil & 48 & 500 \\
\hline AIDS & Diarrhoea, weight loss & Cryptospordium $\mathrm{sp}$ & Cryptospordium $\mathrm{sp}$ & 0 & $<6$ \\
\hline AIDS & Diarrhoea, weight loss & Nil & Nil & - & - \\
\hline AIDS & Diarrhoea, weight loss & Nil & Nil & 39 & 77 \\
\hline AIDS & Herpes zoster & Nil & Nil & - & - \\
\hline AIDS & Diarrhoea, weight loss, Herpes zoster & NK & Nil & - & - \\
\hline AIDS & Diarrhoea, weight loss & Cryptospordium $\mathrm{sp}$ & Microspordium $\mathrm{sp}$ & - & - \\
\hline AIDS & Diarrhoea, weight loss & Nil & Strongyloides & - & - \\
\hline Negative & Abdominal pain & Nil & Nil & & \\
\hline Negative & Asymptomatic & Nil & Nil & & \\
\hline Negative & Asymptomatic & Nil & Nil & & \\
\hline Negative & Asymptomatic & Nil & $\begin{array}{l}\text { Schistosoma } \\
\text { mansoni }\end{array}$ & & \\
\hline Negative & Asymptomatic & Nil & Spirochaetosis & & \\
\hline Negative & Diarrhoea, weight loss, abdominal pain & Nil & Nil & & \\
\hline Negative & Asymptomatic & Nil & Nil & & \\
\hline
\end{tabular}

NK, not known; ARC, AIDS related complex; PGL, persistent generalised lymphadenopathy.

\section{Results}

CLINICAL DATA

Table 1 summarises clinical data for the London and African patients.

\section{JEJUNAL HISTOLOGY}

London patients

Jejunal biopsy specimens from HIV positive male homosexuals showed variable degrees of villous blunting and broadening, or were normal. Villous enterocytes showed only mild focal nuclear irregularity. Apoptotic cells were observed in very few crypts. Cellularity of lamina propria was normal or showed a mild or moderate increase in the density of lymphocytes and plasma cells. Granulomatous inflammation was not a feature of any of the biopsy specimens.

\section{African subjects}

Jejunal biopsy specimens from HIV positive and negative Ugandan subjects showed a spectrum of villous architecture, ranging from normality to severe flattening with blunted and broadened forms. Villous enterocytes in the flattened biopsy specimens showed variable nuclear irregularity and stratification, and crowded intraepithelial lymphocytes. Apoptotic bodies were sparse in crypt epithelium.
Cellularity of lamina propria in some biopsy specimens fell within normal limits, but in others there was a moderate to severe increase in the density of lymphocytes and plasma cells. No evidence of neoplasia or granulomatous inflammation was seen in any biopsy specimen.

MUCOSAL QUANTITATION

Figure 1 shows the results of quantitation of $\mathrm{S}: \mathrm{V}$ ratio and CL.

Mucosal architecture index

London subjects - $\mathrm{S}: \mathrm{V}$ ratio was lower in the biopsy specimens in the group of HIV positive patients (38.5 (9.50)) than in the group of control subjects $(51.2 \quad(5.56)) \quad(s=150.0$, $\mathrm{p}=0.0044)$. There was no correlation between $\mathrm{S}: \mathrm{V}$ ratio and clinical stage of HIV disease.

African subjects-There was no significant difference in $\mathrm{S}: \mathrm{V}$ ratio between biopsy specimens from HIV positive subjects (35.1 (10.91)) and those from HIV negative control subjects $(35.9$ (9.53)) ( $\mathrm{s}=87.0, \mathrm{p}=0.867)$. There was no difference in $\mathrm{S}: \mathrm{V}$ ratio between biopsy specimens with and without detected enteropathogens.

London and African control subjects-The range of $\mathrm{S}: \mathrm{V}$ ratio in London control subjects was 45.6-62.0; the interquartile range (con- 

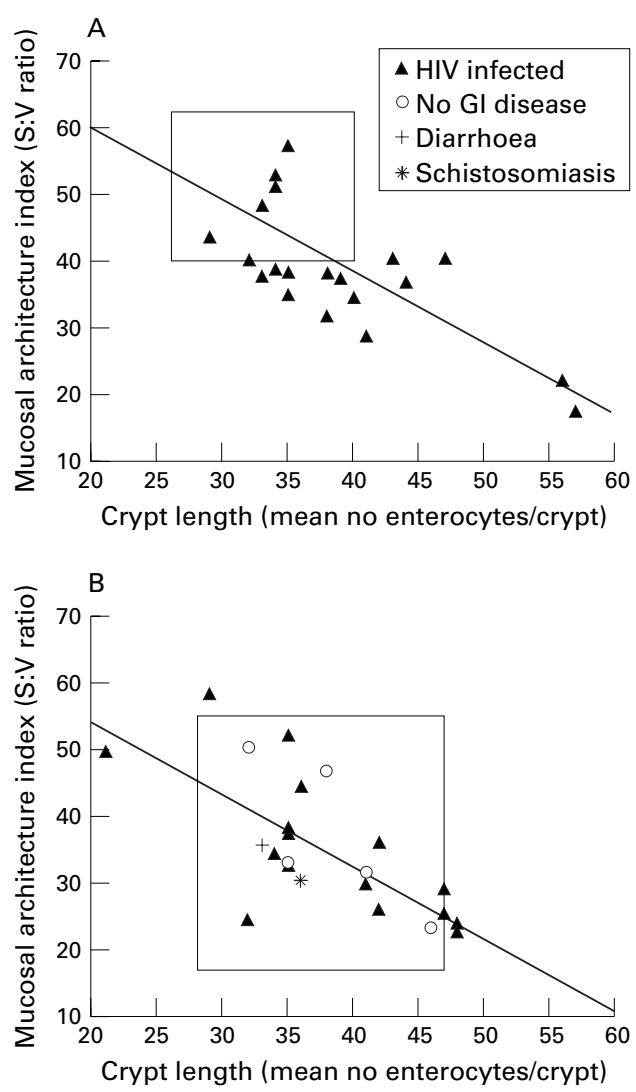

Figure 1 Correlation of mucosal architecture index and mean crypt length in: $(A)$ all HIV infected $(n=20)$ and control $(n=7)$ London subjects combined; and $(B)$ all HIV infected $(n=16)$ and control $(n=7)$ African subjects. Boxes represent normal range (mean (2SD)) of London subjects and control range (mean (2SD)) of African subjects.

taining $50 \%$ of the data) was 7.4. The range of $\mathrm{S}: \mathrm{V}$ ratio in African control subjects was 23.450.4; the interquartile range was 13.5.

Crypt length

London subjects - CL was higher in the biopsy specimens of the group of HIV positive patients (38.9 (7.499)) than in the group of control subjects $(32.6(3.51)) \quad(s=54.0, r=0.0157)$. There was no correlation between the degree of crypt hyperplasia and the clinical stage of HIV disease.

African subjects-There was no significant difference in CL between biopsy specimens from HIV positive subjects $(37.9$ (7.59)) and those from HIV negative control subjects (37.3 (4.89)) ( $\mathrm{s}=78.5, \mathrm{p}=0.737)$. There was no difference in CL between biopsy specimens with and without detected enteropathogens.

London and African control subjects-The range of CL in London control subjects was 28-39; the interquartile range was 4 . The range of CL in African control subjects was 32-46; the interquartile range was 8 .

\section{Correlation of mucosal architecture index and crypt length}

London and African subjects combinedThere were statistically significant negative correlations between $\mathrm{S}: \mathrm{V}$ ratio and $\mathrm{CL}$ in biopsy specimens from all HIV infected and control London and African subjects com- bined ( $r=-0.67, \mathrm{n}=50, \mathrm{p}=0.0001)$, in biopsy specimens from all HIV infected and control London subjects alone $(r=-0.63, \mathrm{n}=27$, $\mathrm{p}=0.0004$ ), and in biopsy specimens from all HIV infected and control African subjects alone $(r=-0.68, \mathrm{n}=23, \mathrm{p}=0.0003) . \mathrm{S}: \mathrm{V}$ ratio was statistically significantly greater in the biopsy specimens of the group of all London subjects $(n=27 ; 41.8(10.27))$ than in the group of all African subjects $(n=23 ; 35.3$ $(10.30))(\mathrm{s}=464.0, \mathrm{p}=0.018)$. There was no statistically significant difference in CL between biopsy specimens from all London subjects $(n=27 ; 37.2(7.20))$ and those from all African subjects $(n=23 ; 37.7$ (6.78)) ( $s=636.0$, $\mathrm{p}=0.339$ ). The fitted lines using least squares methods for all London subjects alone and for all African subjects alone are marked in figs $1 \mathrm{~A}$ and $1 \mathrm{~B}$ respectively. The gradients of these lines for London and African subjects are the same and the lines are separated by approximately six units of mucosal architecture index or mean crypt length.

London subjects-There was a highly significant negative correlation $(r=-0.60$, $\mathrm{p}=0.0055$ ) between $\mathrm{S}: \mathrm{V}$ ratio and CL in biopsy specimens from HIV antibody positive subjects - that is, flattening of villi (decreasing mucosal architecture index) correlated strongly with hyperplasia of crypts (increasing mean crypt length). Jejunal biopsy specimens from 15 of 20 HIV antibody positive subjects showed an abnormally low $\mathrm{S}: \mathrm{V}$ ratio with or without an increase in CL (normal range = mean (2SD) of normal biopsy specimens) (fig $1 \mathrm{~A})$.

African subjects-There was a significant negative correlation between $S: V$ ratio and CL in biopsy specimens from all HIV positive subjects $(r=-0.67, \mathrm{n}=16, \mathrm{p}=0.0047)$. The correlation between $\mathrm{S}: \mathrm{V}$ ratio and CL in biopsy specimens from all HIV negative control subjects analysed was significant at the $10 \%$ level $(r=-0.71, \mathrm{n}=7, \mathrm{p}=0.0713)$. While this negative correlation is large, it did not reach significance at the $5 \%$ level because of the small sample size. Thus, flattening of villi (decreasing mucosal architecture index) correlated with hyperplasia of crypts (increasing mean crypt length) in both subject groups. Jejunal biopsy specimens from 12 of $16 \mathrm{HIV}$ antibody positive subjects showed $\mathrm{S}: \mathrm{V}$ ratio and CL within the control range (control range $=$ mean $(2 \mathrm{SD})$ of HIV negative African biopsy specimens) (fig 1B). Of the four remaining specimens, two showed an increased CL, one a decreased CL, and one an increased S:V ratio; an opportunistic pathogen was detected in specimens from two of these four subjects.

HIV infected cells

Positive (HIV infected) cells were seen in jejunal mucosal biopsy specimens of eight of the 10 HIV infected patients studied (table 1). No positive staining was seen in any of the biopsy specimens from control subjects or tissue processed in the absence of the primary monoclonal antibody. HIV infected Jurkat cells stained positively. 
Positive cells occurred only in the lamina propria; no cells with convincing nuclear or cytoplasmic positivity were detected in the epithelial layer. Infected cells in the lamina propria were mononuclear cells with the appearance of lymphocytes and macrophages. In those eight patients (two London and six African) in whom positive cells were detected in the jejunal mucosa, the lowest density of positive cells in the mucosa of African patients (approximately 50 infected cells per $\mathrm{mm}^{2}$ of muscularis mucosae) was twice the greatest mucosal density of positive cells in the London patients (approximately 25 cells per $\mathrm{mm}^{2}$ of muscularis mucosae). However, caution must be used in attributing this variation to genuine differences in viral load, given the sampling error inherent in examining small biopsy specimens.

\section{Discussion}

Several studies of jejunal biopsy specimens taken from patients infected with HIV have shown a reduction in villous surface area. ${ }^{46-11}$ Our study confirms this finding in HIV positive male homosexuals living in a temperate climate, in whom $60 \%$ of patients had a mucosal architecture index in jejunal mucosa below the normal range in the absence of detectable opportunistic enteric pathogens. The absence of opportunistic infection in this group is unexpected, however, and the influence of occult pathogens on jejunal structure cannot of course be excluded. Also, the apparent absence of correlation between disease stage and severity of disease in the mucosa may be spurious, given the small number of patients studied.

The jejunal mucosa of normal indigenous European subjects consists predominantly of finger shaped villi. Very few mucosal biopsy specimens taken from healthy Ugandan African individuals have measurements which fall within the normal range for Europeans in the United Kingdom. ${ }^{22}$ On light microscopic examination, villous height is reduced and the width is increased, and some mucosal biopsy specimens show an increased inflammatory infiltrate in the lamina propria. These minor abnormalities in small bowel morphology described in asymptomatic residents of several tropical countries have been labelled tropical enteropathy. ${ }^{23}$ Of the jejunal biopsy specimens taken from the five African control subjects in this study which showed crypt hyperplasia and/or villous flattening as judged by the criteria for normal London subjects, three were taken from such asymptomatic individuals; the two others were taken from subjects with diarrhoea or a detectable enteric pathogen. The aetiology of tropical enteropathy remains unclear, but it seems probable that repeated acute gastrointestinal infections of bacterial or viral origin are implicated. In African patients with HIV infection, the spectrum of opportunistic enteric infections is similar to that found in HIV positive patients in a temperate climate, although the burden of infection is greater. ${ }^{24-28}$

This is the first study to compare small bowel morphology of African HIV infected patients with HIV negative control subjects and HIV positive patients in an industrialised country. The jejunal morphology of HIV negative Africans is compared with the jejunal mucosa of healthy subjects resident in a temperate climate in this study. Biopsy specimens from HIV negative African subjects show a greater range of villous surface area and mean crypt length than specimens from normal London subjects, with a shift towards flatter villi and longer crypts. However, an important finding also is that there is no difference in villous surface area and crypt length between HIV infected and uninfected African patients. This suggests that the net effects of HIV on jejunal morphology cannot be separated clearly from the effects of other organisms in the African environment. Enteropathy induced by HIV in the African patient may be masked by the mucosal pathology induced by other stimuli, including other enteric infections and the factors responsible for the lesion seen in tropical enteropathy.

While it is accepted that the small intestine of patients infected with HIV may show villous atrophy, there is no such consensus in published work about the effect of HIV on crypt length. Some work ${ }^{6}$ doubts the significance of HIV in causing jejunal pathology. Other studies support the notion of HIV enteropathy, but they have produced contradictory data, namely crypt hyperplasia with normal ${ }^{9}$ or increased ${ }^{8}$ mitotic activity, and crypts of normal length with decreased ${ }^{10}$ or increased ${ }^{11}$ mitotic activity. Furthermore, the pathogenesis of the archetypal crypt hyperplastic villous atrophy seen in coeliac disease is controversial. Studies using foetal intestinal explants maintained in vitro, however, provide strong evidence that crypt cell hyperplasia is a rapid event after lamina propria $T$ cell activation, and it precedes villous atrophy. ${ }^{29}{ }^{30}$ This time course of events casts doubt on the alternative model of crypt hyperplastic villous atrophy, which suggests that enterocyte shedding and villous collapse stimulate compensatory crypt hyperplasia. ${ }^{31}$

The negative correlation shown in this study between mean crypt length and villous surface area in all the biopsy specimens examined indicates that there is an inverse relation between crypt cell population size and villous cell population size in jejunal mucosa. We suggest from this observation that crypt cell hyperplasia is the primary mucosal lesion in an enteropathy, driving immature enterocytes onto the sides of villi and reducing absorptive villous surface area by shifting the crypt/villus junction in a luminal direction. It is apparent from our data that the crypt/villus structure of the jejunal mucosa responds in the same way to enteric infection in the subjects living in temperate or tropical climates, since the gradients of the correlation lines between mucosal architecture index and mean crypt length are the same in the two subject groups. However, the two slopes are separated by about six units of mucosal architecture index or mean crypt length, and there is a statistically significant difference in mucosal architecture index between London and African subjects. This implies that there is a fundamental difference in mucosal structure between London and 
African individuals, with mucosal crypts in the jejunum of the African subject supporting on average villi of somewhat smaller surface area. We may also infer that mucosal HIV infection in a patient resident in a temperate climate stimulates crypt cell proliferation and encroachment of enterocytes onto villi with a luminal shift of the crypt/villus junction; any hyperplastic response of the crypts to HIV infection in a patient in the tropics may be masked by the response of crypts to other enteric pathogens.

Support for this model of HIV enteropathy has come from a morphometric study of foetal intestinal mucosal explants infected with $\mathrm{HIV}^{32}$ We suggest that infection of lamina propria cells in the jejunum by HIV may alter cytokine regulation and stimulate crypt cell proliferation resulting in the mucosal lesion seen in HIV enteropathy. Preliminary studies have produced contradictory data on the role of cytokine production in the jejunal mucosa in HIV enteropathy. ${ }^{33} 34$ Further work is in progress to elucidate abnormalities of cytokine expression in this disease.

We thank Mrs J Jones for secretarial assistance, and M Frost and $\mathrm{J}$ Chapman for technical assistance. This work has appeared in part as two abstracts (Gut 1987:28:A1399; and 7th International Conference on AIDS 1991, MB2226, Vol 1, p. 238).

1 Sharpstone D, Gazzard B. Gastrointestinal manifestations of HIV infection. Lancet 1996;348:379-83.

2 Grunfeld C, Feingold K. Metabolic disturbances and wasting in the acquired immunodeficiency syndrome. $N$ Engl $f$ Med 1992;327:329-35.

3 Griffin GE. Malabsorption, malnutrition and HIV disease. Baillieres Clin Gastroenterol 1990;4:361-73.

4 Kotler DP, Gaetz HP, Lange M, et al. Enteropathy associated with the acquired immunodeficiency syndrome. Ann Intern Med 1984;101:421-8.

5 Gillin JS, Shike M, Alcock N, et al. Malabsorption and mucosal abnormalities of the small intestine in the acquired immunodeficiency syndrome. Ann Intern Med 1985;102: 619-22. 6 Kotler DP, Francisco A, Clayton F, et al. Small intestinal
injury and parasitic diseases in AIDS. Ann Intern Med injury and parasitic

7 Connolly GM, Forbes A, Gazzard BG. Investigation of seemingly pathogen-negative diarrhoea in patients infected with HIV-1. Gut 1990;31:886-9.

8 Heise C, Dandekar S, Kumar P, et al. Human immunodeficiency virus infection of enterocytes and mononuclear cells in human jejunal mucosa. Gastroenterology 1991;100:15217 .

9 Greenson JK, Belitsos PC, Yardley JH, et al. AIDS enteropathy: occult enteric infections and duodenal mucosal alterations in chronic diarrhoea. Ann Intern Med 1991;114:366-72.

10 Ullrich R, Zeitz M, Heise W, et al. Small intestinal structure and function in patients infected with human immunodeficiency virus (HIV): evidence for HIV-induced enteropathy. Ann Intern Med 1989;111:15-21.

11 Cummins AG, La Brooy JT, Stanley DP, et al. Quantitative histological study of enteropathy associated with HIV infection. Gut 1990;31:317-21.
12 Ullrich R, Heise W, Bergs C, et al. Gastrointestinal symptoms in patients infected with human immunodeficiency virus: relevance of infective agents isolated from gastrointestinal tract. Gut 1992;33:1080-4

13 Miller ARO, Griffin GE, Batman P, et al. Jejunal mucosal architecture and fat absorption in male homosexuals infected with human immunodeficiency virus. $Q \mathcal{F ~ M e d}$ 1988;69:1009-19.

14 Batman PA, Miller ARO, Forster SM, et al. Jejunal enteropathy associated with human immunodeficiency virus infection: quantitative histology. $f$ Clin Pathol 1989;42:275-81.

15 Centers for Disease Control: classification system for human T-lymphotropic virus type III/lymphadenopathyassociated virus infection. Ann Intern Med 1986;105:234-7.

16 Widy-Wirski R, Berkley S, Downing R, et al. Evaluation of the WHO clinical case definition for AIDS in Uganda. 7AMA 1988;260:3286-9.

17 Dunnill MS, Whitehead R. A method for the quantitation of small intestinal biopsy specimens. F Clin Pathol 1972;25: 243-6.

18 Wright NA, Zucoloto S, Bramble M, et al. Assessment of villus and crypt population sizes in human small intestinal biopsies. Gut 1979;20:921

19 Wright N, Watson A, Morley A, et al. Cell kinetics in flat (avillous) mucosa of the human small intestine. Gut 1973; 14:701-10.

20 Wright NA, Appleton DR, Marks J, et al. Cytokinetic studies of crypts in convoluted human small intestinal mucosa. f Clin Pathol 1979;32:462-70.

21 Cordell J, Falini B, Erber W, et al. Immunoenzymatic labelling of monoclonal antibodies using immune complexes of alkaline phosphatase anti-alkaline phophatase (APAAP). $\mathcal{F}$ Histochem Cytochem 1984;32:219-29.

22 Cook GC, Kajubi SK, Lee FD. Jejunal morphology of the African in Uganda. F Pathol 1969;98:157-69.

23 Wood GM, Gearty JC, Cooper BT. Small bowel morphology in British Indian and Afri-Caribbean subjects: evidence of tropical enteropathy. Gut 1991;32:256-9.

24 Lucas SB, De Cock KM, Hounnou A, et al. Contribution of tuberculosis to slim disease in Africa. BMF 1994;308: 1531-3

25 Henry MC, de Clercq D, Lokombe B, et al. Parasitological observations of chronic diarrhoea in suspected AIDS adult patients in Kinshasa (Zaire). Trans $R$ Soc Trop Med Hyg 1986;80:309-10.

26 Sewankambo N, Mugerwa RD, Goodgame R, et al. Enteropathic AIDS in Uganda. An endoscopic, histological and microbiological study. AIDS 1987;1:9-13.

27 Conlon CP, Pinching AJ, Perera CU, et al. HIV-related enteropathy in Zambia: a clinical, microbiological, and histological study. Am f Trop Med Hyg 1990;42:83-8.

28 Kelly P, Baboo KS, Wolff M, et al. The prevalence and aetiology of persistent diarrhoea in adults in urban Zambia. Acta Tropica 1996;61:183-90.

29 Macdonald TT, Spencer J. Evidence that activated mucosal $\mathrm{T}$ cells play a role in the pathogenesis of enteropathy in human small intestine. $\mathcal{F}$ Exp Med 1988;167:1341-9.

30 Ferreira R da C, Forsyth LE, Richman PI, et al. Changes in the rate of crypt epithelial cell proliferation and mucosal morphology induced by a T-cell-mediated response in human small intestine. Gastroenterology 1990;98:1255-63.

31 Marsh MN, Loft DE, Garner VG, et al. Time/dose responses of coeliac mucosae to graded oral challenges with Frazer's fraction III of gliadin. Eur 7 Gastroenterol Hepatol 1992;4:667-73.

32 Batman PA, Fleming SC, Sedgwick PM, et al. HIV infection of human foetal intestinal explant cultures induces epithelial cell proliferation. AIDS 1994;8:161-7.

33 McGowan I, Radford-Smith G, Jewell DP. Cytokine gene expression in HIV-infected intestinal mucosa. AIDS 1994; 8:1569-75.

34 Snijders F, van Deventer SJH, Bartelsman JFW, et al. Diarrhoea in HIV-infected patients: no evidence of cytokinemediated inflammation in jejunal mucosa. AIDS 1995;9: 367-73. 